\title{
Lack of association between the APLNR variant rs9943582 with ischemic stroke in the Chinese Han GeneID population
}

\author{
Pengyun Wang ${ }^{1,2, *}$, Chuchu Wang ${ }^{3, *}$, Sisi Lí, ${ }^{2,}$, Binbin Wang ${ }^{4}$, Liang Xiong ${ }^{1}$, Xin Tu ${ }^{2}$, \\ Qing K. Wang ${ }^{2,5,6}$ and Cheng-Qi Xu' ${ }^{2}$ \\ ${ }^{1}$ Department of Clinical Laboratory, Liyuan Hospital, Tongji Medical College, Huazhong University of Science and Technology, \\ Wuhan, P. R. China \\ ${ }^{2}$ Key Laboratory of Molecular Biophysics of the Ministry of Education, Cardio-X Institute, College of Life Science and Technology \\ and Human Genome Research Center, Huazhong University of Science and Technology, Wuhan, P.R. China \\ ${ }^{3}$ Zhengzhou University, School of Life Sciences, Zhengzhou, P.R. China \\ ${ }^{4}$ National Research Institute for Family Planning, Beijing, P.R. China \\ ${ }^{5}$ Center for Cardiovascular Genetics, Department of Molecular Cardiology, Lerner Research Institute, Department of \\ Cardiovascular Medicine, Cleveland Clinic, Cleveland, Ohio, USA \\ ${ }^{6}$ Department of Molecular Medicine, Department of Genetics and Genome Science, Case Western Reserve University, \\ Cleveland, Ohio, USA \\ *These authors contributed equally to this work \\ Correspondence to: Cheng-Qi Xu, email: cqxu@mail.hust.edu.cn \\ Qing K. Wang, email: qkwang@mail.hust.edu.cn
}

Keywords: atherosclerosis, ischemic stroke, association studies, APLNR, Rs9943582

Received: June 30, $2017 \quad$ Accepted: November 04, $2017 \quad$ Published: November 21, 2017

Copyright: Wang et al. This is an open-access article distributed under the terms of the Creative Commons Attribution License 3.0 (CC BY 3.0), which permits unrestricted use, distribution, and reproduction in any medium, provided the original author and source are credited.

\section{ABSTRACT}

Stroke is one of the most common causes of death worldwide. Genetic risk factors have been found to play important roles in the pathology of ischemic stroke. In a previous genome-wide association study, a functional variant (rs9943582, $-154 \mathrm{G} / \mathrm{A}$ ) in the $5^{\prime}$ flanking region of the apelin receptor gene (APLNR) was shown to be significantly associated with stroke in the Japanese population. However, the association required validation in other ethnicities. To validate the genetic relationship between APLNR and ischemic stroke in the Chinese Han population, we genotyped rs9943582 in a case-control population containing 1,158 ischemic stroke patients and 1,265 common controls enrolled from the GeneID database, and performed a genetic association study. We detected no allelic or genotypic associations between rs9943582 and ischemic stroke in the Chinese Han GeneID population, although the study population provided sufficient statistical power. This finding indicates that the association between the APLNR variant and ischemic stroke or atherosclerosis may need further validation.

\section{INTRODUCTION}

Stroke is one of the commonest causes of death worldwide [1]. In China, 1.5-2 million new cases of stroke occur annually, accounting for around $20 \%$ of all deaths [2-5]. Ischemic stroke is the main type of stroke, which is responsible for about $87 \%$ of stroke cases [6]. It is usually caused by a thrombus or embolus blocking blood flow to the brain, and atherosclerosis of the small or large arteries in the brain is the major cause for the formation of thrombi [7].

Epidemiological studies have indicated that genetic and environmental risk factors and their interactions play important roles in the pathology of ischemic stroke. Largescale genome-wide association studies (GWAS) have identified loci conferring risk to ischemic stroke, including variants in 11q12.1 (APLNR), 12p13 (NINJ2), 12q24 (ALDH2), 7p21 (HDAC9), 9p21 (ANRIL), 4q25 (PITX2), 
16q22 (ZFHX3), 9q34 (ABO), and 1p13.2 (TSPAN2) [8-14]. Candidate gene association studies also identified variants that confer risk to ischemic stroke in several susceptibility genes including ALOX5AP, VKORC1, NOS3, PCSK9, PDE4D, and SGK1 [15-20].

In a previous GWAS conducted by Hata et al., a functional variant in the $5^{\prime}$ flanking region (rs9943582, $-154 \mathrm{G} / \mathrm{A}$ ) of the apelin receptor gene (AGTRL1 or $A P L N R$ ) was found to be significantly associated with risk of stroke in the Japanese population. The apelin receptor is a G-protein-coupled receptor, which was identified as the receptor for the adipokine apelin [21-22]. In a mouse model, $A P L N R$ was found to be associated with atherosclerosis [23].

To validate the genetic relationship between the APLNR variant and ischemic stroke in the Chinese Han population, we evaluated the contribution of rs9943582 to the genetic susceptibility of ischemic stroke in the Chinese GeneID population including 1,158 ischemic stroke patients and 1,265 controls.

\section{RESULTS}

\section{Characteristics of study subjects}

The case group of 1,158 ischemic stroke patients had an average age of $60.6 \pm 8.4$ years, females accounted for $41 \%, 55 \%$ of the subjects had hypertension, and $13.5 \%$ had type 2 diabetes mellitus. In controls, the average age of the 1,265 subjects was $61.7 \pm 10.2$ years, $38.4 \%$ were females, $37.6 \%$ had hypertension, and $9.4 \%$ had type 2 diabetes. The mean age of subjects in the control group was significantly higher than those in the case group $(P<0.001)$ (Table 1), while the proportion of subjects with hypertension and type 2 diabetes was significantly higher in the case group than the control group. We also observed that serum total cholesterol levels and low density lipoprotein cholesterol levels (LDL-C) were significantly higher in cases than controls group, while the levels of high density lipoprotein cholesterol (HDL-C) were significantly lower in cases than controls. There was no significant difference in serum triglyceride content between the two groups (Table 1).

\section{No significant association between $A P L N R$ variant rs9943582 with ischemic stroke in the Chinese Han GeneID population}

Under the population parameter setting of the effect size or odds ratio (OR) of 1.3 for stroke [14], and the minor allele frequency of 0.252 for rs 9943582 (according to 1000 Genome CHB datasets), our case-control population can provide a statistical power of $98 \%$ to detect an association between rs9943582 and ischemic stroke with a type I error of 0.05 . Therefore, our GeneID samples were sufficiently large to test the association between rs9943582 and ischemic stroke, and the possibility of obtaining false positives or negatives was limited.

We genotyped rs9943582 in cases and controls, and compared the frequency of alleles in each group (Table 2). The rs9943582 A allele was observed at a frequency of $26.3 \%$ in 1,158 ischemic stroke patients, compared with $25.6 \%$ in 1,265 controls. Statistical analysis indicated that there was no significant difference in allelic frequency between cases and controls: the observed $P$ value $(P-o b s)$ was 0.57 , and the OR was 1.04 (95\% confidence interval (CI): 0.91-1.18) (Table 2). After adjusting for potential confounders such as age, gender, hypertension, diabetes mellitus, smoking status, and lipid concentrations (total cholesterol, triglycerides, HDL-C, and LDL-C), the association remained insignificant $(\mathrm{OR}=0.99$ with an adjusted $P(P$-adj) of 0.86$)$ (Table 2$)$.

We conducted subgroup analysis of the study subjects by gender, and found that the allelic association between variant rs 9943582 and ischemic stroke was not significant in either the female population (475 cases versus 486 controls, $P_{o b s}=0.69, \mathrm{OR}=0.96 ; P_{a d j}=0.41$, $\mathrm{OR}=1.00)$ or the male population (683 cases versus 779 controls, $P_{o b s}=0.28, \mathrm{OR}=1.10 ; P_{a d j}=69, \mathrm{OR}=0.97$ ) (Table 2).

We also divided the study subjects according to hypertension status, and again found that the association remained insignificant. In subjects with hypertension (637 cases versus 476 controls), the $P_{\text {obs }}$ was $0.75(\mathrm{OR}=$ $0.96)$ and the $P_{a d j}$ was $0.24(\mathrm{OR}=1.13)$, while the $P_{o b s}$ was $0.50(\mathrm{OR}=1.06)$ and the $P_{a d j}$ was $0.40(\mathrm{OR}=0.94)$ in the subgroup without hypertension.

Further analyses included the genotypic association under three common genetic models: additive, dominant, or recessive (Table 3). No significant genotypic association was identified between variant rs9943582 and ischemic stroke under all three genetic models. Adjusting for covariates of sex, age, hypertension, smoking history, type 2 diabetes, and lipid concentration also found no significant association (Table 3 ).

\section{DISCUSSION}

In the present study, we performed a case-control genetic association analysis to determine whether the APLNR variant rs9943582, previously identified in a GWAS as conferring risk to ischemic stroke in the Japanese population [14], was also a risk factor for ischemic stroke in the Chinese GeneID population. No significant association between rs9943582 with ischemic stroke was detected in our population of 1,158 ischemic stroke patients and 1,265 controls.

Previous functional research identified an association between the apelin receptor and apelin with atherosclerosis [23]. However, no genetic associations between rs 9943582 and coronary artery disease, which shares a similar pathogenic mechanism to that of 
Table 1: Basic characteristics of the ischemic stroke case control popolation

\begin{tabular}{lccc}
\hline Characteristic & $\begin{array}{c}\text { Cases } \\
(\boldsymbol{n}=\mathbf{1 1 5 8})\end{array}$ & $\begin{array}{c}\text { Controls } \\
(\boldsymbol{n}=\mathbf{1 2 6 5})\end{array}$ & $<0.001$ \\
\hline Age (years) & $60.6 \pm 8.4$ & $61.7 \pm 10.2$ & $>0.05$ \\
Gender, female, $n(\%)$ & $475(41.0 \%)$ & $486(38.4 \%)$ & $<0.001$ \\
Hypertension, $n,(\%)$ & $637(55 \%)$ & $476(37.6 \%)$ & $<0.01$ \\
Diabetes, $n,(\%)$ & $158(13.5 \%)$ & $119(9.4 \%)$ & $<0.001$ \\
Total Cholesterol (mmol/L) & $4.67 \pm 1.17$ & $4.26 \pm 1.12$ & $>0.05$ \\
Triglyceride $(\mathrm{mmol} / \mathrm{L})$ & $1.82 \pm 0.65$ & $1.79 \pm 0.71$ & $<0.001$ \\
HDL-C $(\mathrm{mmol} / \mathrm{L})$ & $1.11 \pm 0.33$ & $1.20 \pm 0.36$ & $<0.001$ \\
LDL-C $(\mathrm{mmol} / \mathrm{L})$ & $2.66 \pm 1.06$ & $2.45 \pm 1.04$ & $<0.001$ \\
Smoker $n(\%)$ & $361(31.7 \%)$ & $345(27.3 \%)$ & \\
\hline
\end{tabular}

Data are shown as mean $+/-$ standard deviation (SD) for quantitative variables and $n(\%)$ for qualitative variables.

HDL-c: high density lipoprotein cholesterol levels; LDL-c, low density lipoprotein cholesterol levels.

${ }^{*}$ Age at the first diagnosis of the disease.

Table 2: Analysis of allelic association of rs9943582 with ischemic stroke

\begin{tabular}{|c|c|c|c|c|c|c|c|c|}
\hline \multirow{2}{*}{$\begin{array}{l}\text { Cohort } \\
(n, \text { case/control) }\end{array}$} & \multicolumn{3}{|c|}{ Number of Genotype } & \multirow{2}{*}{$\begin{array}{c}\text { Freq_A } \\
\text { (case/control) }\end{array}$} & \multicolumn{2}{|c|}{ Observed $^{*}$} & \multicolumn{2}{|c|}{ Adjust $^{\dagger}$} \\
\hline & & Case & Control & & P-obs & $\begin{array}{c}\text { OR } \\
(95 \% \mathrm{CI})\end{array}$ & P-adj & $\begin{array}{c}\text { OR } \\
(95 \% \mathrm{CI})\end{array}$ \\
\hline \multirow{3}{*}{$\begin{array}{l}\text { Entire population } \\
(1158 / 1265)\end{array}$} & AA & 97 & 92 & \multirow{3}{*}{$0.263 / 0.256$} & \multirow{3}{*}{0.57} & \multirow{3}{*}{$\begin{array}{c}1.04 \\
(0.91-1.18)\end{array}$} & \multirow{3}{*}{0.86} & \multirow{3}{*}{$\begin{array}{c}0.99 \\
(0.87-1.13)\end{array}$} \\
\hline & $\mathrm{AG}$ & 416 & 464 & & & & & \\
\hline & GG & 645 & 709 & & & & & \\
\hline \multirow{3}{*}{$\begin{array}{l}\text { Male } \\
(683 / 779)\end{array}$} & $\mathrm{AA}$ & 57 & 61 & \multirow{3}{*}{$0.276 / 0.258$} & \multirow{3}{*}{0.28} & \multirow{3}{*}{$\begin{array}{c}1.10 \\
(0.93-1.29)\end{array}$} & \multirow{3}{*}{0.69} & \multirow{3}{*}{$\begin{array}{c}0.97 \\
(0.81-1.15)\end{array}$} \\
\hline & $\mathrm{AG}$ & 263 & 278 & & & & & \\
\hline & GG & 363 & 440 & & & & & \\
\hline \multirow{3}{*}{$\begin{array}{l}\text { Female } \\
(475 / 486)\end{array}$} & AA & 40 & 30 & \multirow{3}{*}{$0.245 / 0.253$} & \multirow{3}{*}{0.69} & \multirow{3}{*}{$\begin{array}{c}0.96 \\
(0.78-1.18)\end{array}$} & \multirow{3}{*}{0.41} & \multirow{3}{*}{$\begin{array}{c}1.00 \\
(0.88-1.36)\end{array}$} \\
\hline & $\mathrm{AG}$ & 153 & 187 & & & & & \\
\hline & GG & 282 & 269 & & & & & \\
\hline \multirow{3}{*}{$\begin{array}{l}\text { Non-Hypertension } \\
(521 / 789)\end{array}$} & AA & 38 & 66 & \multirow{3}{*}{$0.256 / 0.245$} & \multirow{3}{*}{0.50} & \multirow{3}{*}{$\begin{array}{c}1.06 \\
(0.89-1.27)\end{array}$} & \multirow{3}{*}{0.50} & \multirow{3}{*}{$\begin{array}{c}0.94 \\
(0.78-1.13)\end{array}$} \\
\hline & $\mathrm{AG}$ & 191 & 254 & & & & & \\
\hline & GG & 292 & 469 & & & & & \\
\hline \multirow{3}{*}{$\begin{array}{l}\text { Hypertension } \\
(637 / 476)\end{array}$} & AA & 59 & 26 & \multirow{3}{*}{$0.269 / 0.275$} & \multirow{3}{*}{0.75} & \multirow{3}{*}{$\begin{array}{c}0.97 \\
(0.80-1.17)\end{array}$} & \multirow{3}{*}{0.24} & \multirow{3}{*}{$\begin{array}{c}1.13 \\
(0.92-1.38)\end{array}$} \\
\hline & $\mathrm{AG}$ & 225 & 210 & & & & & \\
\hline & GG & 353 & 240 & & & & & \\
\hline
\end{tabular}

Freq_A: Frequency of A allele.

"Uncorrected $P$ value and odds ratio (OR) using Chi-square tests with Pearson's $2 \times 2$.

${ }^{\dagger}$ Adjusted $P$ value by multivariate logistic regression analysis for potential confounders including age, gender, smoking, hypertension, diabetes mellitus and lipid concentrations (Tch, TG, HDL-c and LDL-c).

stroke, were identified in our previous study of Chinese individuals or in research by Kunihiko et al. into Japanese and Korean populations [24-25]. Similarly, our present case-control association analysis detected no allelic or genotypic association between rs9943582 and ischemic stroke in the Chinese Han GeneID population, although the study population provided sufficient statistical power. Our result is consistent with the study by Zhang et al., which also showed a negative association between rs9943582 and the age of onset and clinical outcomes of ischemic stroke in the Chinese population [26]. 
Table 3: Analysis of genotypic association of rs9943582 with ischemic stroke in Chinese Han GeneID population under different genetic models of inheritance

\begin{tabular}{lccccc}
\hline Cohorts & Model & $\boldsymbol{P}_{-} \boldsymbol{o b s} \boldsymbol{s}^{*}$ & OR (95\% CI) & $\boldsymbol{P}_{-} \boldsymbol{a d j ^ { \dagger }}$ & OR (95\% CI) \\
\hline \multirow{2}{*}{ Entire cohort } & Dominant & 0.89 & $1.01(0.86-1.19)$ & 0.60 & $1.05(0.89-1.24)$ \\
$(1,158 / 1,265)$ & Recessive & 0.28 & $1.18(0.88-1.59)$ & 0.59 & $0.91(0.87-1.24)$ \\
& Additive & 0.54 & n.a & 0.87 & $1.01(0.89-1.15)$ \\
\hline
\end{tabular}

"Uncorrected $P$ value and odds ratio (OR) using Chi-square tests with Pearson's $2 \times 2$.

${ }^{\dagger}$ Adjusted $P$ value by multivariate logistic regression analysis for potential confounders including age, gender, smoking, hypertension, diabetes mellitus and lipid concentrations (Tch, TG, HDL-c and LDL-c).

n.a.: no data.

In the present study, we excluded ischemic stroke patients with subarachnoid hemorrhages, embolic brain infarctions, and those shown by computed tomography (CT) or magnetic resonance imaging (MRI) data to have subcritical hemispheric lesions $<1.5 \mathrm{~cm}$ in diameter, which are commonly classified as lacunar strokes. In fact, most of the patients in the present study had cortical or cerebellar lesions and brain stem or subcortical hemispheric infarcts $>1.5 \mathrm{~cm}$ in diameter, which are considered to potentially be of large artery atherosclerosis origin. Therefore, our findings may represent the association between rs 9943582 and ischemic stroke of large artery atherosclerosis origin, so further study may be required to determine whether it confers risk to other subtypes of ischemic stroke such as lacunar stroke, cardioembolic stroke, and infarcts of uncertain cause.

One limitation of the present study is that only one variant (rs9943582) was selected to investigate the genetic association between APLNR and ischemic stroke risk; therefore, our study cannot exclude the possibility that other APLNR variants confer risk to ischemic stroke. The association between other polymorphisms in the APLNR genomic region and ischemic stroke requires additional study.

In conclusion, our study indicates that the $A P L N R$ variant rs 9943582 is not associated with ischemic stroke in the Chinese Han population, and that the association between this variant and ischemic stroke or atherosclerosis needs further validation. The findings in this study further emphasize the population heterogeneity of genetic susceptibility of ischemic stroke.

\section{MATERIALS AND METHODS}

\section{Study populations}

The subjects in the present case-control genetic association study were enrolled from the GeneID database, which is an ongoing study of the Chinese Han population that has collected $>80,000$ DNA samples and available clinical data. The GeneID database aims to identify susceptibility genes or other risk factors for cardiovascular and cerebrovascular diseases in the Chinese Han population [25, 27-35]. This study was approved by the Ethics Committee of Huazhong University of Science and Technology and conforms to the Declaration of Helsinki guidelines. Written informed consent was obtained from all study subjects.

The 1,158 ischemic stroke patients were receiving treatment for ischemic stroke at Wuhan hospitals, whereas the 1,265 controls were individuals subjected to physical examination at the same hospitals. All subjects were selfreported to be of Chinese Han origin.

The diagnosis of ischemic stroke was according to standard World Health Organization criteria [36]. The clinical diagnosis was made by at least two independent neurologists based on a medical history of stroke, stroke signs by neurological examination, and cerebral ischemia by CT or MRI images. We selected patients with ischemic stroke only, and excluded those with subarachnoid hemorrhages, embolic brain infarctions, brain tumors, and those with a relevant brain stem or subcritical hemispheric lesions $<1.5 \mathrm{~cm}$ dimeter based on CT or MRI data. The ischemic stroke subtype classification was according to the Trial of ORG 10172 in Acute Stroke Treatment [37]. We enrolled healthy individuals as controls according to physical tests and medical history.

Other basic demographic and clinical characteristics were obtained including age, gender, hypertension, type 2 diabetes mellitus, and lipid concentrations (total cholesterol, LDL-C, HDL-C, and triglycerides). Hypertension was defined as a systolic blood pressure of $\geq 140 \mathrm{mmHg}$ or a diastolic blood pressure of $90 \mathrm{mmHg}$. Type 2 diabetes was defined as receiving ongoing therapy for diabetes or a fasting plasma glucose level of $\geq 126 \mathrm{mg} / \mathrm{dL}$ after at least $8 \mathrm{~h}$ of fasting, or a $2 \mathrm{~h}$ plasma glucose level of $\geq 200 \mathrm{mg} / \mathrm{dL}$ during an oral glucose tolerance test. 


\section{Single nucleotide polymorphism (SNP) genotyping}

Genomic DNA was prepared from venous blood samples using the Wizard ${ }^{\circledR}$ Genomic DNA Purification Kit (Promega, WI, USA).

Genotyping for SNP 9943582 was performed by SYTO-9 fluorescent dye-based high-resolution melting (HRM) analysis as previously described [37]. Briefly, the PCR reaction mixture of $25 \mu \mathrm{l}$ contained $2.5 \mu \mathrm{l}$ of $10 \times \mathrm{PCR}$ Buffer (containing $15 \mathrm{mM} \mathrm{MgCl}$ ), $0.4 \mu \mathrm{l}$ of dNTPs $(10 \mathrm{mM}$ ), $0.4 \mu \mathrm{l}$ of each primer $(10 \mu \mathrm{M}), 1 \mu \mathrm{l}$ of template DNA (25 ng/ $\mu \mathrm{l}), 5 \mu \mathrm{mol} / \mathrm{L}$ of SYTO-9 fluorescent dye, $0.2 \mathrm{U}$ of Taq DNA polymerase, and $\mathrm{ddH}_{2} \mathrm{O}$. The forward PCR primer was 5'-ACCACTTCCTGCCTGCCCTTTA-3' and the reverse primer was 5'-ACACCCTCCTTGCTCCCTACCA-3'. PCR conditions were: $95^{\circ} \mathrm{C}$ for $5 \mathrm{~min}$, followed by 40 cycles of $95^{\circ} \mathrm{C}$ for $15 \mathrm{~s}, 55^{\circ} \mathrm{C}$ for $15 \mathrm{~s}$, and $72^{\circ} \mathrm{C}$ for $15 \mathrm{~s}$, with a final elongation step of $72^{\circ} \mathrm{C}$ for $10 \mathrm{~min}$. PCR products were analyzed and the genotype of each individual was determined using the HRM program. Three DNA samples with known genotypes of $\mathrm{CC}, \mathrm{AC}, \mathrm{AA}$ were included as positive controls, and one negative control of $\mathrm{ddH}_{2} \mathrm{O}$ without genomic DNA was also included in each genotyping assay. The total success rate of HRM genotyping was 95.2\%.

HRM genotyping results were validated by direct DNA sequence analysis of 48 randomly selected subjects. The genotypes obtained from HRM analysis were shown to be $100 \%$ concordant with those from Sanger sequencing analysis.

\section{Statistical analysis}

Statistical analysis was performed as previously described [17, 38]. The allelic frequency in cases and controls was compared by Pearson's $2 \times 2$ contingency tables and chi-square tests as implemented in PLINK version 1.06. $P$ values and corresponding ORs with $95 \%$ CIs were computed. Multivariate logistic regression analysis was performed using SPSS version 17.0 by adjusting for risk factors (age, sex, hypertension, smoking history, type 2 diabetes, and lipid concentrations).

The statistical power analysis was performed using a free program (Power and Simple Size Calculation, 3.0.12 version) for a case-control design (http://biostat. mc.vanderbilt.edu/wiki/Main/PowerSampleSize) [39]. The statistical power of the case-control study was calculated using specific parameters, including the minor allele frequency ( 0.252 for rs9943582 according to CHB 1000 Genomes data), OR (1.3 according to a previous study by Hata et al. [14]), the numbers of cases and controls, and the type I error of 0.05 . The null hypothesis could be rejected if $\mathrm{OR}=1$ with probability (power). The program uses an uncorrected chi-squared statistical method to evaluate the null hypothesis [40].

\section{Author contributions}

P.W., C.W and S.L. contributed equally to this study. Study concept and design: C. X and Q.K.W. Acquisition, Analysis and interpretation of data: P.W., C.W., S.L., B.W., and L.X., Drafting of the manuscript: P.W. and C. X. Critical revision of the manuscript for important intellectual content: X. T. and Q.K.W. Statistical analysis: P.W. and S.L.

\section{ACKNOWLEDGMENTS AND FUNDING}

We thank the study subjects for their participation and support of this study and all members of the GeneID team for help and assistance. This study was supported by This study was supported by the National Natural Science Foundation of China Program (81600263, 31671302 and 31430047), the Natural Science Foundation of Hubei Province (2016CFB224) and the Fundamental Research Funds for the Central Universities (HUST0118170142).

\section{CONFLICTS OF INTEREST}

The authors have declared no conflicts of interest specific to this article.

\section{REFERENCES}

1. Boehme AK, Esenwa C, Elkind MS. Stroke Risk Factors, Genetics, and Prevention. Circ Res. 2017; 120:472-95.

2. Feigin VL, Norrving B, Mensah GA. Global Burden of Stroke. Circ Res. 2017; 120:439-48.

3. Kim AS, Cahill E, Cheng NT. Global Stroke Belt: Geographic Variation in Stroke Burden Worldwide. Stroke. 2015; 46:3564-70.

4. O'Neill D. Global burden of stroke: an underestimate. Lancet. 2014; 383:1205.

5. Sun H, Zou X, Liu L. Epidemiological factors of stroke: a survey of the current status in china. J Stroke. 2013; 15:109-14.

6. Kinlay S. Changes in stroke epidemiology, prevention, and treatment. Circulation. 2011; 124: e494-6.

7. Markus HS. Stroke genetics. Hum Mol Genet. 2011; 20:R124-31.

8. Rosand J, Mitchell BD, Ay H, de Bakker PI, Gwinn K, Kittner SJ, Lindgren A, Meschia JF, Pulit SL, Sudlow CL. Loci associated with ischaemic stroke and its subtypes (SiGN). Lancet Neurol. 2016; 15:174-84.

9. Network NSG, Consortium ISG. Loci associated with ischaemic stroke and its subtypes ( $\mathrm{SiGN})$ : a genome-wide association study. Lancet Neurol. 2016; 15:659-707.

10. Kilarski LL, Achterberg S, Devan WJ, Traylor M, Malik R, Lindgren A, Pare G, Sharma P, Slowik A, Thijs V. 
Meta-analysis in more than 17,900 cases of ischemic stroke reveals a novel association at 12q24. 12. Neurology. 2014; 83:678-85.

11. Traylor M, Farrall M, Holliday EG, Sudlow C, Hopewell JC, Cheng YC, Fornage M, Ikram MA, Malik R, Bevan S. Genetic risk factors for ischaemic stroke and its subtypes (the METASTROKE collaboration): a meta-analysis of genome-wide association studies. Lancet Neurol. 2012; 11:951-62.

12. Bellenguez C, Bevan S, Gschwendtner A, Spencer CC, Burgess AI, Pirinen M, Jackson CA, Traylor M, Strange A, Su Z, Band G, Syme PD, Malik R, et al. Genome-wide association study identifies a variant in HDAC9 associated with large vessel ischemic stroke. Nat Genet. 2012; 44:328-33.

13. Ikram MA, Seshadri S, Bis JC, Fornage M, DeStefano AL, Aulchenko YS, Debette S, Lumley T, Folsom AR, van den Herik EG. Genomewide association studies of stroke. N Engl J Med. 2009; 360:1718-28.

14. Hata J, Matsuda K, Ninomiya T, Yonemoto K, Matsushita T, Ohnishi Y, Saito S, Kitazono T, Ibayashi S, Iida M, Kiyohara Y, Nakamura Y, Kubo M. Functional SNP in an Sp1-binding site of AGTRL1 gene is associated with susceptibility to brain infarction. Hum Mol Genet. 2007; 16:630-9.

15. Lõhmussaar E, Gschwendtner A, Mueller JC, Org T, Wichmann E, Hamann G, Meitinger T, Dichgans M. ALOX5AP gene and the PDE4D gene in a central European population of stroke patients. Stroke. 2005; 36:731-6.

16. Helgadottir A, Gretarsdottir S, Clair DS, Manolescu A, Cheung J, Thorleifsson G, Pasdar A, Grant S, Whalley L, Hakonarson H. Association between the gene encoding 5-lipoxygenase-activating protein and stroke replicated in a Scottish population. Am J Hum Genet. 2005; 76:505-9.

17. Xu C, Wang F, Wang B, Li X, Li C, Wang D, Xiong X, Wang P, Lu Q, Wang X. Minor allele C of chromosome 1p32 single nucleotide polymorphism rs11206510 confers risk of ischemic stroke in the Chinese Han population. Stroke. 2010; 41:1587-92.

18. Bevan S, Dichgans M, Gschwendtner A, Kuhlenbäumer G, Ringelstein E, Markus HS. Variation in the PDE4D Gene and Ischemic Stroke Risk A Systematic Review and Metaanalysis on 5200 Cases and 6600 Controls. Stroke. 2008; 39:1966-71.

19. Dahlberg J, Smith G, Norrving B, Nilsson P, Hedblad B, Engström G, Lövkvist H, Carlson J, Lindgren A, Melander O. Genetic variants in serum and glucocortocoid regulated kinase 1, a regulator of the epithelial sodium channel, are associated with ischaemic stroke. J Hypertens. 2011; 29:884-9.

20. Wang Y, Zhang W, Zhang Y, Yang Y, Sun L, Hu S, Chen J, Zhang C, Zheng Y, Zhen Y, Sun K, Fu C, Yang T, et al. VKORC1 haplotypes are associated with arterial vascular diseases (stroke, coronary heart disease, and aortic dissection). Circulation. 2006; 113:1615-21.
21. Langelaan DN, Bebbington EM, Reddy T, Rainey JK. Structural insight into G-protein coupled receptor binding by apelin. Biochemistry. 2009; 48:537-48.

22. Yu XH, Tang ZB, Liu LJ, Qian H, Tang SL, Zhang DW, Tian GP, Tang CK. Apelin and its receptor APJ in cardiovascular diseases. Clin Chim Acta. 2014; 428:1-8.

23. Chun HJ, Ali ZA, Kojima Y, Kundu RK, Sheikh AY, Agrawal R, Zheng L, Leeper NJ, Pearl NE, Patterson AJ, Anderson JP, Tsao PS, Lenardo MJ, et al. Apelin signaling antagonizes Ang II effects in mouse models of atherosclerosis. J Clin Invest. 2008; 118:3343-54.

24. Hinohara K, Nakajima T, Sasaoka T, Sawabe M, Lee BS, Ban JM, Park JE, Izumi T, Kimura A. Validation of the association between AGTRL1 polymorphism and coronary artery disease in the Japanese and Korean populations. J Hum Genet. 2009; 54:554-6.

25. Wang P, Xu C, Wang C, Wu Y, Wang D, Chen S, Zhao Y, Wang X, Li S, Yang Q, Zeng Q, Tu X, Liao Y, et al. Association of SNP Rs9943582 in APLNR with Left Ventricle Systolic Dysfunction in Patients with Coronary Artery Disease in a Chinese Han GeneID Population. PLoS One. 2015; 10:e0125926.

26. Zhang H, Sun L, Wang H, Cai H, Niu G, Bai Y, Zhang Y, Yang D, Gu M, Xu P, Fan X, Liu X, Xu G. A Study of GWAS-Supported Variants of rs9943582 in a Chinese Han Population with Ischemic Stroke: No Associations with Disease Onset and Clinical Outcomes. J Stroke Cerebrovasc Dis. 2017; 26:2294-2299. https://doi. org/S1052-3057(17)30232-X.

27. Xu C, Yang Q, Xiong H, Wang L, Cai J, Wang F, Li S, Chen J, Wang C, Wang D, Xiong X, Wang P, Zhao Y, et al. Candidate pathway-based genome-wide association studies identify novel associations of genomic variants in the complement system associated with coronary artery disease. Circ Cardiovasc Genet. 2014; 7:887-94.

28. Wang F, Xu CQ, He Q, Cai JP, Li XC, Wang D, Xiong X, Liao YH, Zeng QT, Yang YZ, Cheng X, Li C, Yang R, et al. Genome-wide association identifies a susceptibility locus for coronary artery disease in the Chinese Han population. Nat Genet. 2011; 43:345-9.

29. Cheng $\mathrm{X}$, Shi L, Nie S, Wang F, Li X, Xu C, Wang P, Yang B, Li Q, Pan Z, Li Y, Xia H, Zheng C, et al. The same chromosome 9p21.3 locus is associated with type 2 diabetes and coronary artery disease in a Chinese Han population. Diabetes. 2011; 60:680-4.

30. Xiong X, Xu C, Zhang Y, Li X, Wang B, Wang F, Yang Q, Wang D, Wang X, Li S, Chen S, Zhao Y, Yin D, et al. BRG1 variant rs1122608 on chromosome 19p13.2 confers protection against stroke and regulates expression of pre-mRNA-splicing factor SFRS3. Hum Genet. 2014; 133:499-508.

31. Ren $\mathrm{X}, \mathrm{Xu} \mathrm{C}$, Zhan C, Yang Y, Shi L, Wang F, Wang C, Xia Y, Yang B, Wu G, Wang P, Li X, Wang D, et al. Identification of NPPA variants associated with atrial 
fibrillation in a Chinese GeneID population. Clin Chim Acta. 2010; 411:481-5.

32. Bai Y, Nie S, Jiang G, Zhou Y, Zhou M, Zhao Y, Li S, Wang F, Lv Q, Huang Y, Yang Q, Li Q, Li Y, et al. Regulation of CARD8 expression by ANRIL and association of CARD8 single nucleotide polymorphism rs2043211 (p.C10X) with ischemic stroke. Stroke. 2014; 45:383-8.

33. Tu X, Nie S, Liao Y, Zhang H, Fan Q, Xu C, Bai Y, Wang F, Ren X, Tang T, Xia N, Li S, Huang Y, et al. The IL-33ST2L pathway is associated with coronary artery disease in a Chinese Han population. Am J Hum Genet. 2013; 93:652-60.

34. Yin D, Naji DH, Xia Y, Li S, Bai Y, Jiang G, Zhao Y, Wang X, Huang Y, Chen S, Fa J, Tan C, Zhou M, et al. Genomic Variant in IL-37 Confers A Significant Risk of Coronary Artery Disease. Sci Rep. 2017; 7:42175.

35. Zhou S, Wang H, Wang QK, Wang P, Wang F, Xu C. Loss of heterozygosity detected at three short tandem repeat locus commonly used for human DNA identification in a case of paternity testing. Leg Med (Tokyo). 2017; 24:7-11.

36. Stroke. Recommendations on stroke prevention, diagnosis, and therapy. Report of the WHO Task Force on Stroke and other Cerebrovascular Disorders. Stroke. 1989; 20:1407-31.
37. Adams HP Jr, Bendixen BH, Kappelle LJ, Biller J, Love BB, Gordon DL, Marsh EE. Classification of subtype of acute ischemic stroke. Definitions for use in a multicenter clinical trial. TOAST. Trial of Org 10172 in Acute Stroke Treatment. Stroke. 1993; 24:35-41.

38. Li C, Wang F, Yang Y, Fu F, Xu C, Shi L, Li S, Xia Y, Wu G, Cheng X, Liu H, Wang C, Wang P, et al. Significant association of SNP rs2106261 in the ZFHX3 gene with atrial fibrillation in a Chinese Han GeneID population. Hum Genetics. 2011; 129:239-46.

39. Shi L, Li C, Wang C, Xia Y, Wu G, Wang F, Xu C, Wang P, Li X, Wang D, Xiong X, Bai Y, Liu M, et al. Assessment of association of rs2200733 on chromosome 4q25 with atrial fibrillation and ischemic stroke in a Chinese Han population. Hum Genet. 2009; 126:843-9.

40. Dupont WD, Plummer WD Jr. Power and sample size calculations for studies involving linear regression. Control Clin Trials. 1998; 19:589-601. 